\title{
CHICORIC ACID, A PHYTOCHEMICAL COMPOUND OF SOLENOSTEMON MONOSTACHYUS: POSSIBLE DRUG CANDIDATE FOR THE RELIEF OF ERECTILE DYSFUNCTION
}

\author{
Ben Enoluomen Ehigiator, Adedapo Samuel Adesida \\ Department of Pharmacology and Toxicology, Madonna University Nigeria
}

Idowu Olaposi Omotuyi

Centre for Bio-computing and Drug Development, Adekunle Ajasin University, Nigeria.

\begin{abstract}
Solenostemon monostachyus is commonly used in folkloric treatment of many ailments including erectile dysfunction. In this study, its aphrodisiac component and underlying mechanism were investigated. Behavioural evaluation was done, following the oral administration of three different doses $(100,200$ and $400 \mathrm{mg} / \mathrm{kg})$ of ethanolic extract of $S$. monostachyus, sildenafil citrate (Viagra) and corn oil were used as positive and negative controls respectively. Mounting, intromission and ejaculation frequencies, mating performance, and orientation activities towards females. Result showed a striking effect in male rats. Molecular docking was done and heat map generated to probe the likely mechanism of action as invivo studies compared with sildenafil. A library containing 45 phytocompounds previously characterized from $S$. monostachyus was generated and docked (Autodock Vina) into homology models of Arginase II, Phosphodiesterase 5 and Aromatase. From the docking result above, PDE 5 was identified as a major target for two key compounds, Chicoric acid and Hesperidine. Although the latter violated more than two rules of the Lipinski's rule of oral drug.

Conclusion: The results of this study support that Chicoric acids from S. monostachyus may inhibit the activity of PDE5, leading to relaxation of erectile smooth muscles. This finding may underscore the aphrodisiac potency of $S$. monostachyus
\end{abstract}

Key words; Solenostemon monostachyus, Sildenafil citrate, Phosphodiesterase 5, Chicoric acid, erectile dysfunction.

\section{INTRODUCTION}

Sex is the most cherished, indispensable and an integral part of every individual and can be a cradle of pleasure and satisfaction [1]. It is essential for procreation and general wellbeing, as it bonds a relationship and also has a calming effect. Most men enjoy sexual activity, which may include penetrative intercourse. In order to achieve this successfully, erection has to be sustained till the female partner reaches orgasm. When a male is repeatedly unable to get or keep an erection firm enough for sexual intercourse, Erectile dysfunction is said to have resulted.

Erectile dysfunction, also refered to as "impotence," is commonly managed with the help of aphrodisiacs, An aphrodisiac is any substance or agent (food, drug, scent or device) that stimulates the erotic instinct, induces veneral desire and surges pleasure and performance [2]. the usage of many common medicines such as; blood pressure drugs, suppressants and cimetidine (an ulcer drug) can produce ED as a side effect. Nevertheless, psychological factors such as stress, anxiety, guilt, depression, low self-esteem, and fear of sexual failure cause 10 to 20 percent of ED cases. Other possible causes are smoking, which affects blood flow in veins and arteries, as well ashormonal abnormalities, like inadequate testosterone, overactivity of some enzymes like aromatase and arginase II. The availability of Phosphodiesterase type 5 inhibitors, like tadalafil (Cialis) and sildenafil (Viagra) are the most commonly used aphrodisiac agents, but these drugs cause dizziness, headache, visual disturbance, pulse irregularities, dyspepsia, priapism, diarrhoea and flushing [3]. Any medicinal plant with aphrodisiac tendencies should produce statistically significant increase in mating frequencies [4]

Traditional preparations (herbs) have been reported to have contributed to revolutionary insight in the treatment of sexual inadequacies and have become acceptable all over the world as "instant" treatment. About $80 \%$ of the world's population still rely on local medicines and traditional treatments mainly from plant extracts. Interestingly, herbal medicine is becoming very popular in the developing countries. 
S. monostachyus is an aromatic, medicinal plant that belongs to the family Lamiaceae. In English language, it is called Monkey potato. Its names among some ethnic groups in Nigeria include Ntorikwot (Ibibio) and Olojogbodu (Yoruba). The use of S.monostachyus plant in traditional medicine by the people of Nigeria has been documented [5,6,7]. The phytochemical screening of $S$. monostachyus leaf extract revealed the presence of saponins, tannins, cyanogenic glycosides, flavonoids and alkaloids [8]. Despite the acclaimed use of $S$. monostachyus as sex enhancer in some parts of Nigeria, there seems not to be any substantive information in the open scientific literature with respect to it's clear mechanism of action. Therefore, this study was designed to investigate and establish the traditional aphrodisiac potential of the herb.

\section{MATERIALS AND METHODS}

\section{Collection of Plant materials and identification}

The root of S. monostachyus was obtained in April 2019 from the University of Ibadan. The plant was harvested around the forest near new stadium in Ibadan. The plant was botanically identified and authenticated by Mr. Donatus O. Esimekhuai of the Department of Botany and Microbiology, University of Ibadan, Oyo state, Nigeria. with voucher no UIH -22874 with a specimen deposited at University of Ibadan.

\section{Plant Extract Preparation}

The whole plant of $S$. monostachyus was air dried for 72 $\mathrm{h}$ after which it was oven dried at a temperature of $80^{\circ} \mathrm{C}$ for $72 \mathrm{~h}$. Thereafter, it was blended into powder, using a grinding machine. About $634 \mathrm{~g}$ of the powder was macerated in n-Hexane, ehyl acetate and ethanol (2500 $\mathrm{ml}$ ) for $72 \mathrm{~h}$ with intermittent stirring in the morning and evening. The mixture was filtered on the 3rd day and the filtrate was concentrated using a rotary evaporator. The extract yield weighed $12.13 \mathrm{~g}$ for $\mathrm{n}$-Hexane, 11.83 for ethyl acetate and $12 \mathrm{~g}$ ethanolic extracts. They were stored in the refrigerator for further use.

\footnotetext{
Animals

The male and female albino rats were obtained from the Department of Zoology in the University of Benin, Edo state and kept in the animal house of the Department of Pharmacology and Toxicology, Madonna University, Elele Campus. They were allowed to acclimatize for over 1 week before the experiments commenced. They were given growers feed (Vital feed growers by grand feed cereals, Onitsha.) kept in clean cages with access to water and under normal conditions. The rats with the weight range of $130-150 \mathrm{~g}$ were used for this study. All the animals received humane care according to the criteria outlined in the "Guide for the Care and Use of Laboratory Animals' prepared by the National Academy of Science and published by the National Institute of Health.
}

\section{Phytochemical Screening}

Preliminary phytochemical screening of the root extract of S. monostachyus was carried out using standard methods described by [9] and [10]. The extract was screened for the presence of flavonoids, alkaloids, tannins, terpernoids, saponins and glycosides.

\section{Pilot studies}

Pilot studies was done using graded doses of the three solvent extracts. Ethanolic extract showed more promise and was used for the study.

Acute toxicity study: Healthy male albino rats were starved for 3-4 hr and subjected to acute toxicity studies as per (OECD) Organization of Economic Co-operation and Development guidelines No: 423 [11]. They were divided into 4 groups of 4 animals each and kept singly in separate cages during the experiment. Group 1 represented the control group, which received $10 \mathrm{ml} / \mathrm{kg}$ of distilled water orally. Groups 2- 4 received suspension of ethanolic extraxt of of $S$. monostachyus orally at the doses of 1000, 2000 and $5000 \mathrm{mg} / \mathrm{kg}$ daily for 7 days respectively. The rats were observed continuously for 2 hours for behavioural, neurological and autonomic profile, and for next 24 and 72 hours for any lethality or death

\section{Invivo aphrodisiac studies}

Preparation of male rats: Sexual behaviour training was given to male rats for 10 days. The animal that did not show any sexual interest was replaced by another sexually active rat [12].

Preparation of female rats Oestrus (heat) was developed artificially in female rats by giving clomiphene orally $2-3$ days before mating. Before conducting the experiment the receptivity of female rats was ensured [12].

\section{Preparation of female rats}

Oestrus (heat) was developed artificially in female rats by giving clomiphene citrate $50 \mathrm{mg} / \mathrm{kg}$ body weight (orally), 2 days before conducting the experiment. the receptivity of female rats was ensured.

\section{Grouping of Rats}

The rats were divided into 5 groups each having 4 rats. Group I: Control that was not given any extract but food and water and corn oil

Group II: Sildenafil group as our standard for comparison

Group III: $100 \mathrm{mg} / \mathrm{kg}$ body weight of extract dissolved in corn oil

Group IV:200 mg/kg body weight of extract dissolved in corn oil

Group V: $400 \mathrm{mg} / \mathrm{kg}$ body weight of extract dissolved in corn oil

\section{Observation of behavioural sexual parameters}




\section{International Journal of Engineering Applied Sciences and Technology, 2020 \\ Vol. 4, Issue 11, ISSN No. 2455-2143, Pages 509-518 \\ Published Online March 2020 in IJEAST (http://www.ijeast.com)}

Observation of rats Close observation was made once every week for 14 days for the sexual parameters of the rats which entails;

Mount latency: Time interval (seconds, minutes) from the introduction of the female into the cage and the first mount by the male.

Mount frequency: Mounting is defined as the climbing of one animal by another usually from the posterior end with the intention of introducing one organ into another. Mount may also be operationally defined as the male assuming the copulatory position but failing to achieve intromission. Mount Frequency (MF) is therefore defined as the number of mounts without intromission from the introduction of the female until ejaculation.

Intromission latency: Time interval from the introduction of the female to the first intromission (vaginal penetration) by the male.

Intromission frequency: Intromission is the introduction of one organ or parts into another e.g. the penis into the vagina. Intromission Frequency (IF) is the defined as the number of intromissions from the time of introduction of the female until ejaculation.

Ejaculation latency: Ejaculation is the act of ejecting semen brought about by a reflex action that occurs as the result of sexual stimulation. Ejaculation latency (EL) is therefore the duration from first intromission till ejaculation.

Post ejaculation interval: Time interval between ejaculation and next intromission.

All these parameters were observed for the various groups of rats.

\section{Ligand Library Generation}

Identified secondary metabolites of S.monostachyus employed for this study were determined from published literature and were used in the creation of the ligand library. The secondary metabolites were retrieved from NCBI PubChem database [13]. In Standard Database Format format (2D). The ligand library generated were imported to Maestro and prepared using the [14]. Utilizing Ligprep v4.5[14], Epik v4.3 [15]. With OPLS3 force field, for protonation, stereo-isomerization, tautomers generation, and to attain biological conformer.
Energy minimization was achieved for all tautomeric state at $\mathrm{pH}$ of $7 \pm 2$.

\section{Protein Preparation}

Human Arginase II (1.8 ̊), PDE-5 (2.8 $⿱$ $)$, and Aromatase $(2.75 \AA)$ bound with ligands were retrieved from the PDB [16] With the PDB ID 4I06, 2H42, and 5JKV, respectively. Protein Preparation Wizard [17]. Module in maestro 11.5 was used to prepare each protein complex. Protein structure's missing hydrogen atoms, missing loop, and missing sidechains were fixed while the added hydrogen atoms were optimized at $\mathrm{pH}$ 7.0. Optimized structures were then minimized using the OPLS3 force field by converging heavy atoms to RMSD of $0.3 \AA$.

The protein binding site was identified by utilizing the receptor grid generation tool in maestro 11.5. Receptor grid defines the region of interaction between the protein and the ligand. The co-crystal ligands of each protein were used to identify the binding cavity employing default parameters of van der Waals scaling factor 1.00 and charge cutoff of 0.25 around the binding site residues of the protein structures.

\section{Docking Studies}

Molecular docking studies were performed using Glide v7.8 [16]. Module on maestro 11.5. The ligand library compounds and co-crystal ligands were docked into the binding cavity of the targets using the standard precision algorithm (SP) applying a scaling factor of 0.8 and partial charge cutoff of 0.15 , and the ligand was handled as flexible. Five (5) of the lowest energy poses were selected for post-docking minimization seething the threshold at $0.50 \mathrm{kcal} / \mathrm{mol}$ [16]. Lastly, the binding affinity of the receptor-ligand complex was ranked according to Glide score and ligand pose.

\footnotetext{
ADME/TOX Prediction

The absorption, distribution, metabolism, and excretion of the hit ligands were predicted using the Qikprop module in maestro 11.5. QikProp predicts physically significant descriptors and pharmaceutical features of organic molecules. It uses descriptors that are gotten from molecular structure and calculated molecular properties [18]
} 
Results:

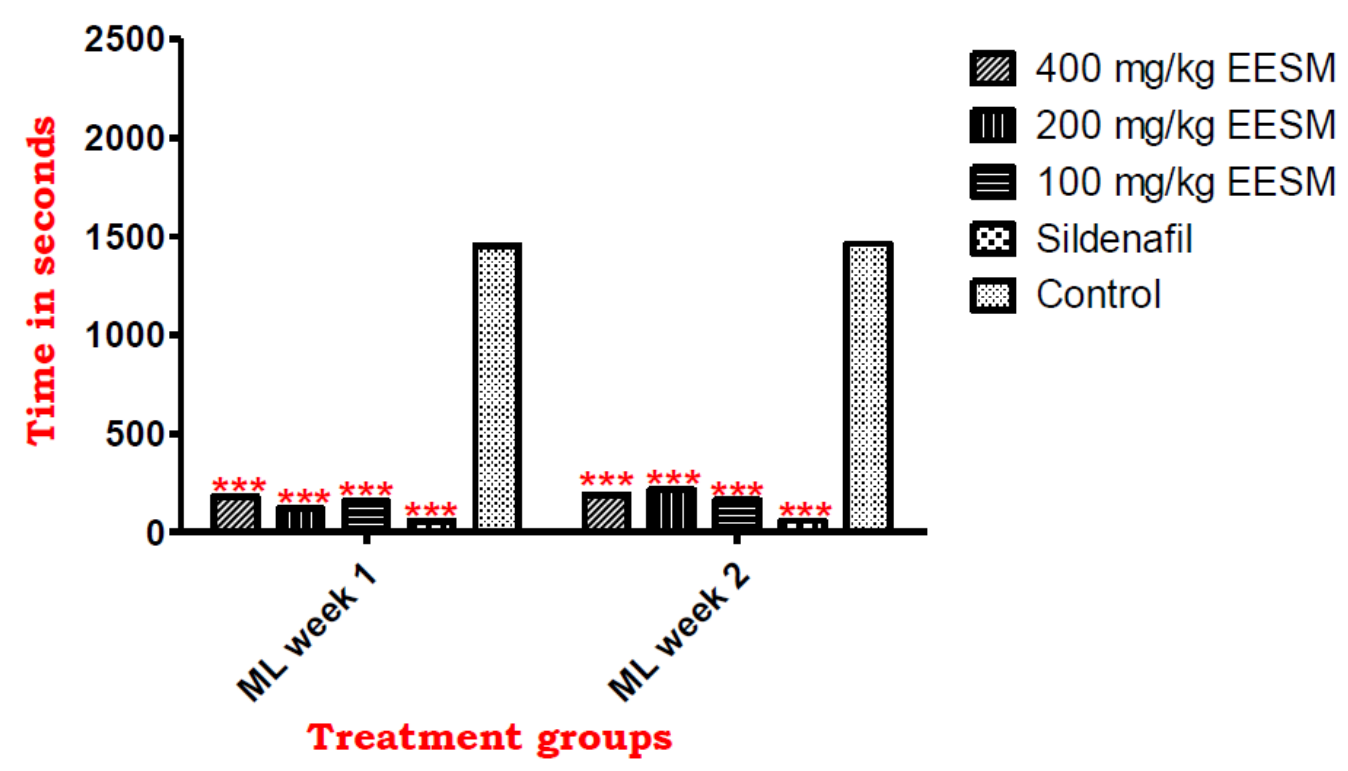

Fig 1. Effect of S. monostachyus on mount latency for 2 weeks in male rats.

Animals per group $(\mathrm{n})=4$. The values are mean \pm SEM.; ${ }^{*} \mathrm{p}<0.05 ;{ }^{* *} \mathrm{p}<0.01 ;{ }^{* * *} \mathrm{p}<0.001$ whe compared with control group. (Two-way ANOVA followed by Bonferonni post hoc test).

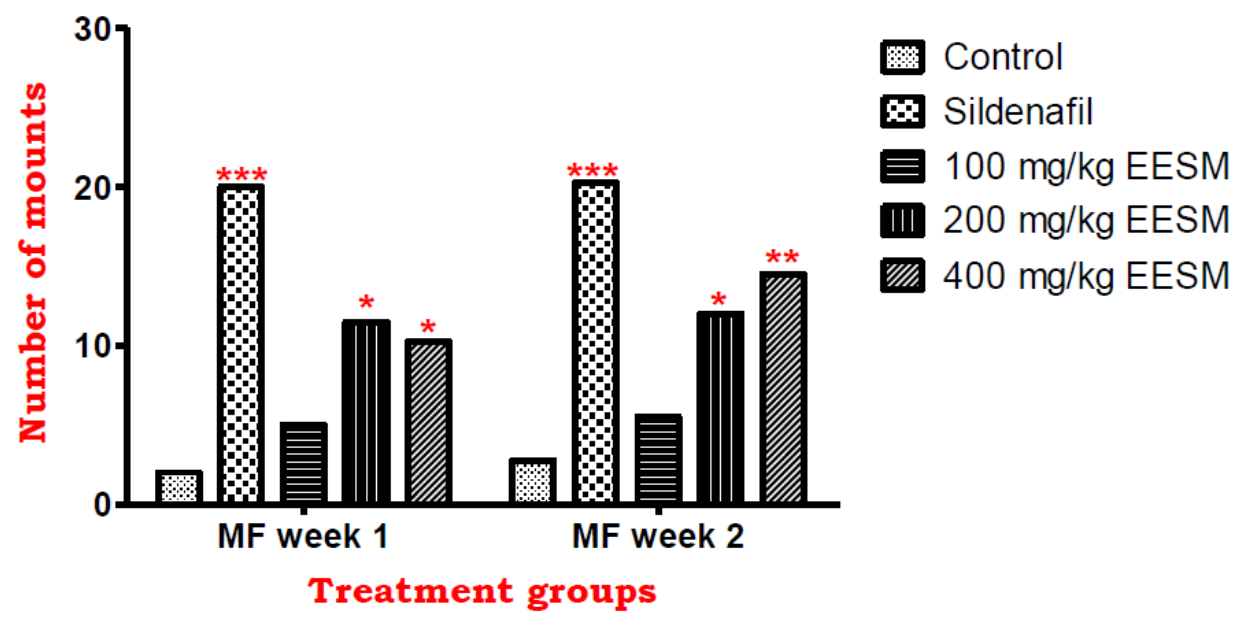

Fig 2. Effect of S. monostachyus on mount frequency in male rats for 2 weeks.

Animals per group $(\mathrm{n})=4$. The values are mean \pm S.E.M.; ${ }^{*} \mathrm{p}<0.05 ;{ }^{* *} \mathrm{p}<0.01 ;{ }^{* * *} \mathrm{p}<0.001$ when compared with control group. (Two-way ANOVA followed by Bonferonni post hoc test). 


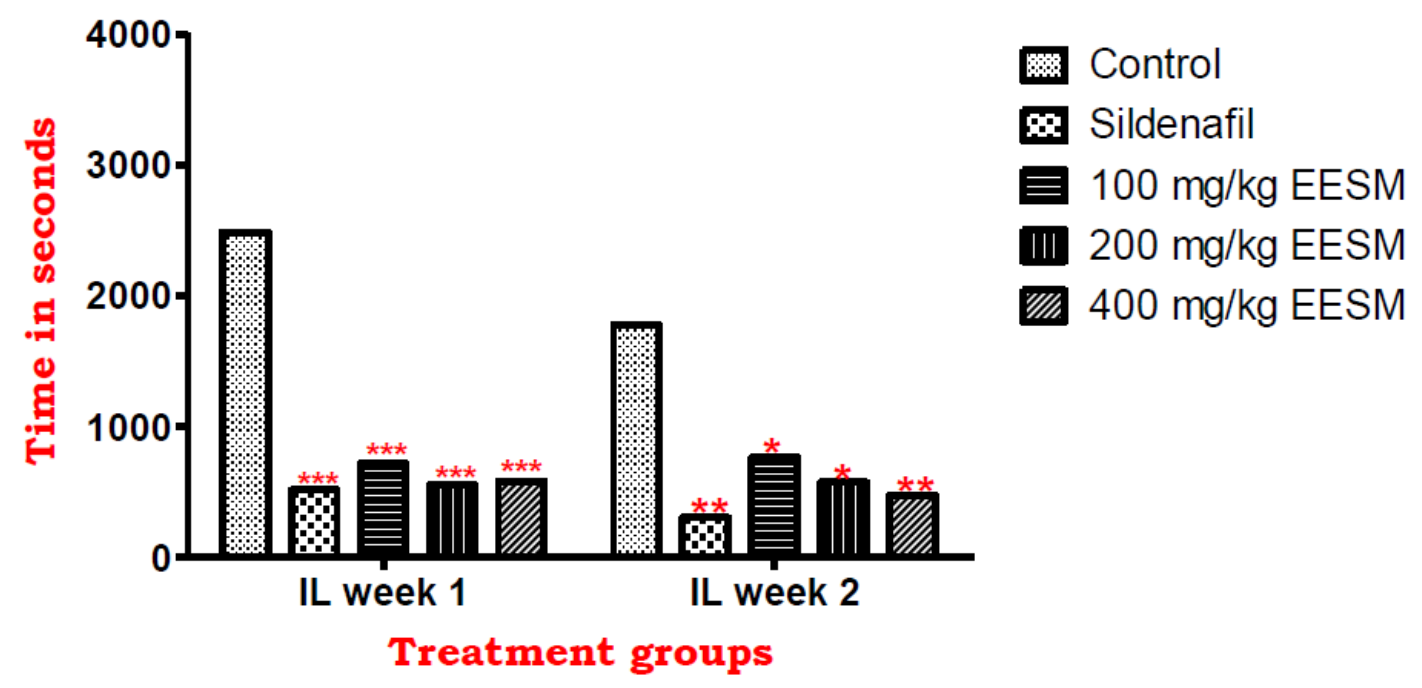

Fig 3. Effect of S. monostachyus on intromission latency in male rats for 2 weeks.

Animals per group $(\mathrm{n})=4$. The values are mean \pm S.E.M.; ${ }^{*} \mathrm{p}<0.05 ;{ }^{* *} \mathrm{p}<0.01 ;{ }^{* * *} \mathrm{p}<0.001$ when compared with control group. (Two-way ANOVA followed by Bonferonni post hoc test).

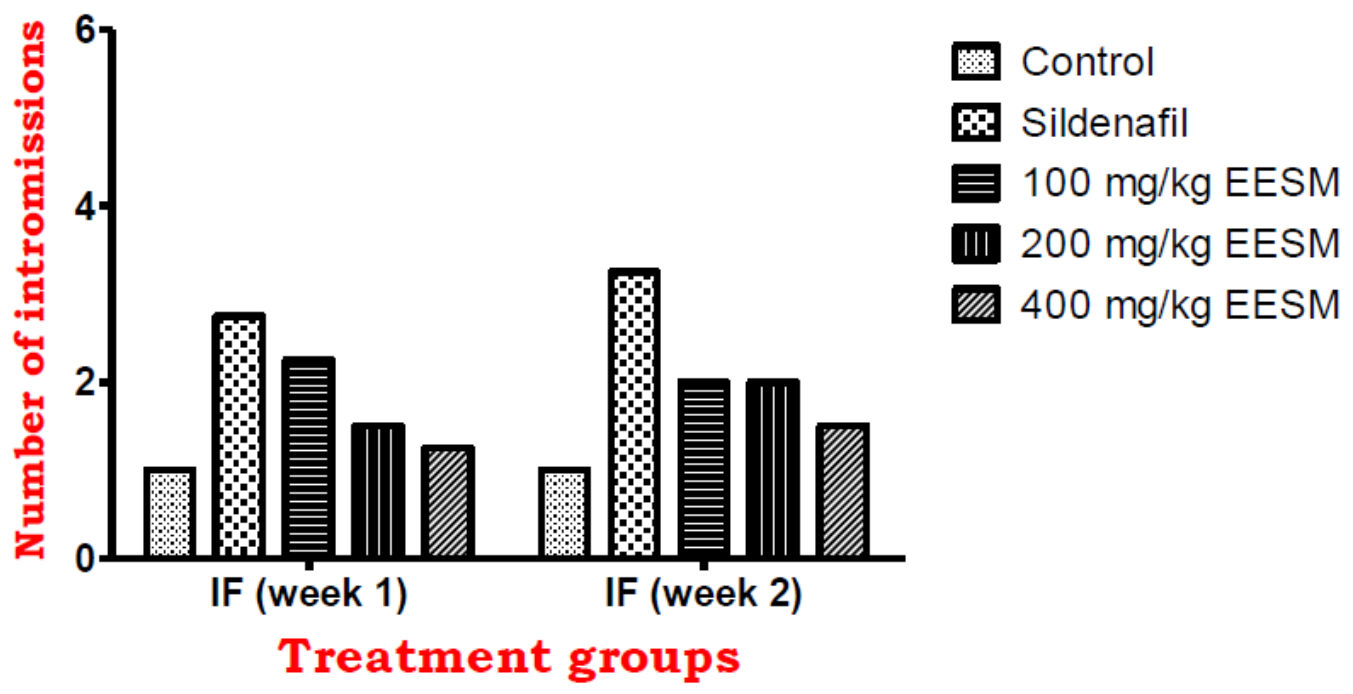

Fig 4. Effect of $S$. monostachyus on intromission frequency in male rats for 2 weeks.

Animals per group $(\mathrm{n})=4$. The values are mean \pm S.E.M.; ${ }^{*} \mathrm{p}<0.05 ;{ }^{* *} \mathrm{p}<0.01 ;{ }^{* * *} \mathrm{p}<0.001$ when compared with control group. (Two-way ANOVA followed by Bonferonni post hoc test). 


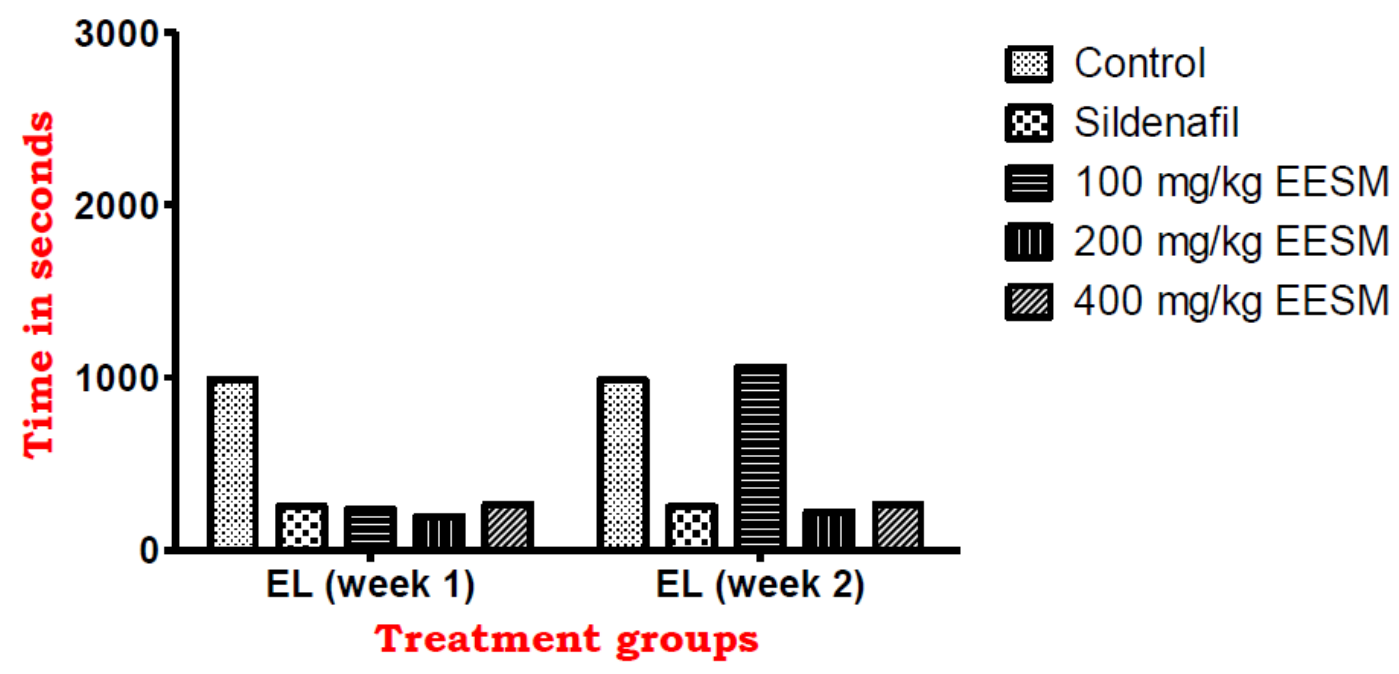

Fig 5. Effect of $S$. monostachyus on Ejaculatory latecy in male rats for 2 weeks.

Animals per group $(\mathrm{n})=4$. The values are mean \pm S.E.M.; ${ }^{*} \mathrm{p}<0.05 ;{ }^{* *} \mathrm{p}<0.01 ;{ }^{* * *} \mathrm{p}<0.001$ when compared with control group. (Two-way ANOVA followed by Bonferonni post hoc test)

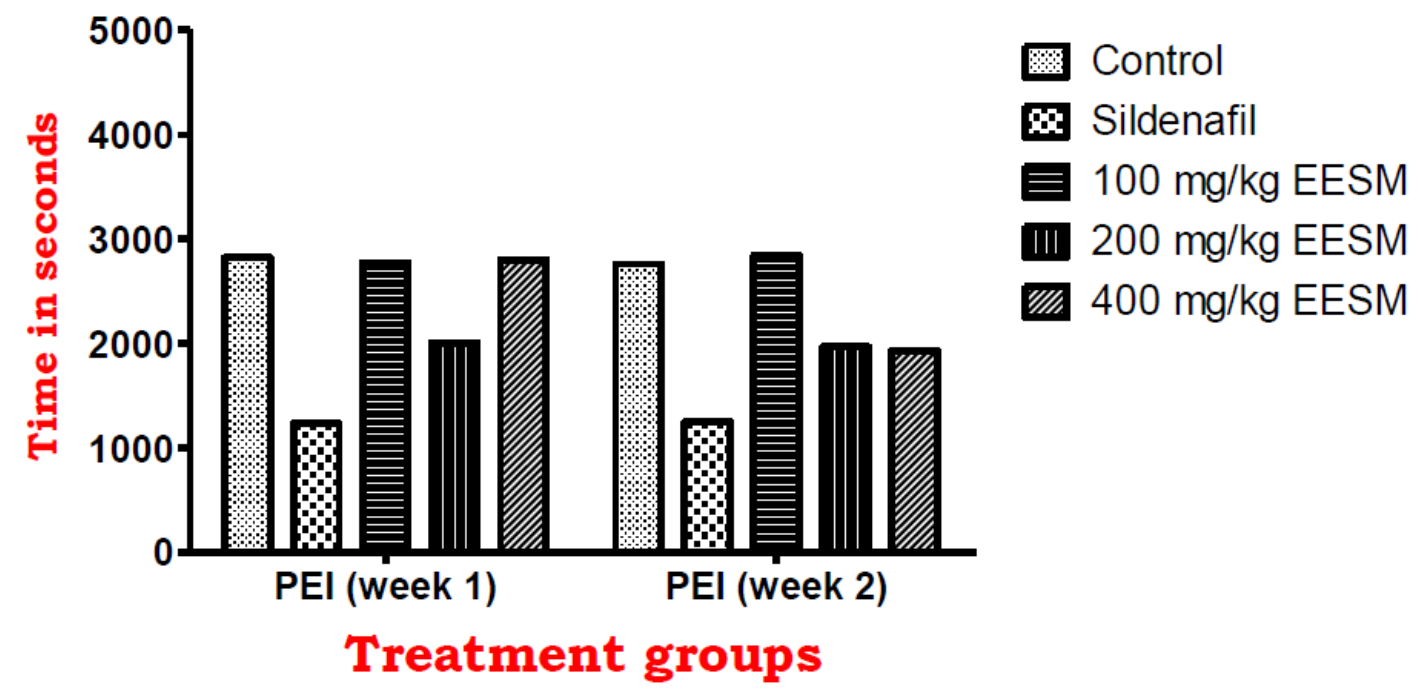

Fig 6. Effect of $S$. monostachyus on Post Ejaculatory Interval in male rats for 2 weeks.

Animals per group $(\mathrm{n})=4$. The values are mean \pm S.E.M.; ${ }^{*} \mathrm{p}<0.05 ;{ }^{* *} \mathrm{p}<0.01 ;{ }^{* * *} \mathrm{p}<0.001$ when compared with control group. (Two-way ANOVA followed by Bonferonni post hoc test). 
International Journal of Engineering Applied Sciences and Technology, 2020

Vol. 4, Issue 11, ISSN No. 2455-2143, Pages 509-518

Published Online March 2020 in IJEAST (http://www.ijeast.com)

Table 2. Showing results of docked scores of some relevant mined compounds of $S$.monostachyus against erectile dysfunction targets.

\section{Docking Result for S. monostachyus}

\begin{tabular}{llccc}
\hline S/N & Compounds & ARGINASE II & PDE5 & AROMATASE \\
\hline 1 & CoLigands & -8.01 & -11.127 & -7.502 \\
2 & Chicoric acid & -5.393 & -9.973 & -7.221 \\
3 & Hesperidin & -5.465 & -9.654 & -8.048 \\
4 & Myricetin & -6.886 & -9.129 & -6.027 \\
5 & Quercetin & -6.624 & -8.819 & -5.776
\end{tabular}

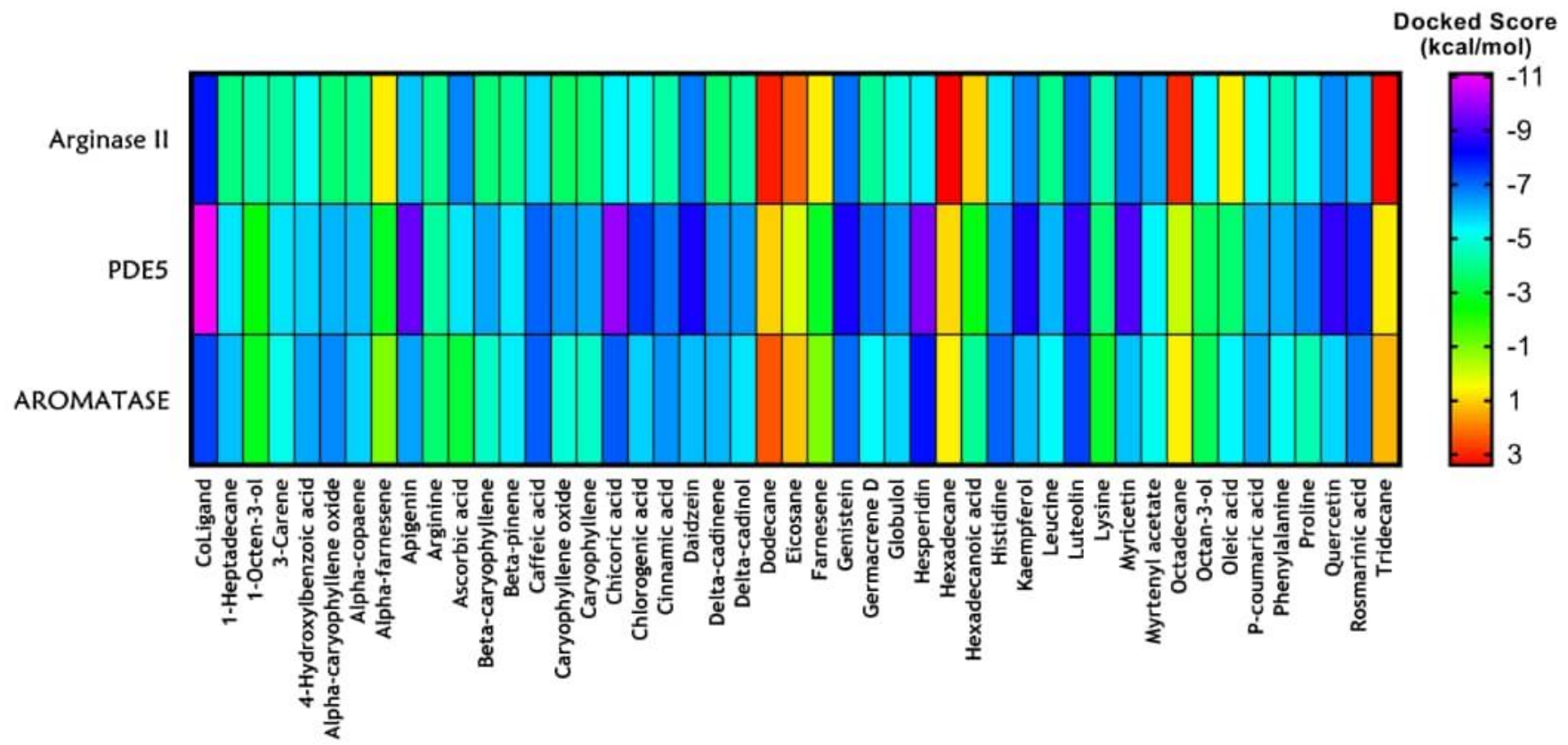

Fig 7. Heat map representation of docking result. The free energy of binding of phytochemicals of W. indica docked into the substrate binding sites of Aromatase, Arginase II and PDE 5, are represented as heat map. (The scale is a spectrum from red $(3 \mathrm{kcal} / \mathrm{mol})$ to pink $(-11 \mathrm{kcal} / \mathrm{mol})$. 
International Journal of Engineering Applied Sciences and Technology, 2020

Vol. 4, Issue 11, ISSN No. 2455-2143, Pages 509-518

Published Online March 2020 in IJEAST (http://www.ijeast.com)

Table 3. Result showing Adme/tox values of the compounds that compared well with

the co crystallized PDE 5 inhibitor.

\begin{tabular}{|l|l|l|l|l|l|}
\hline S/n & Molecule & Molecular weight & donor Hb & Accept Hb & QplogPo/w \\
\hline 1 & PDE5 Co-Ligand & 475.577 & 1 & 11.75 & 1.766 \\
2 & Chicoric acid & 474.37 & 6 & 11 & 0.677 \\
3 & Hesperidin & 610.568 & 7 & 20.05 & -1.48 \\
\hline
\end{tabular}

MW, molecular weight: R.V.: 130-725; donorHB, estimated number of hydrogen bonds

that would be donated by the solute to water molecules in an aqueous solution: R.V.: 0.0-

MW, molecular weight: R.V.: 130-725; donorHB, estimated number of hydrogen bonds that would be donated by the solute to water molecules in an aqueous solution: R.V.: 0.0-6.0; accptHB, estimated number of hydrogen bonds that would be accepted by the solute from water molecules in an aqueous solution: R.V. = 2.0-20.0; QPlogPo/w, predicted octanol/water partition coefficient: R.V. =-2.0 to 6.5; QPlogHERG, predicted IC50 value for blockage of human Ether-a'-go-go related gene $\mathrm{K}+$ channels, $<-5$ = concern; QPPCaco, predicted apparent gut-blood barrier permeability, $<25$ = poor, $>500=$ great; $\mathrm{QP} \log \mathrm{BB}$, predicted brain $/$ blood partition coefficient, -3.0 to 1.2; QPPMDCK, predicted apparent Madin-Darby canine kidney cell permeability, $<25=$ poor, $>500=$ great; $\mathrm{QPlogKhsa}$, prediction of binding to human serum albumin, -1.5 to 1.5 ; HOA, human oral absorption level, 1, 2, 3: 1 = low, 2 = medium; ROF, the number of violations of Lipinski's rule of five; R.V., recommended value.
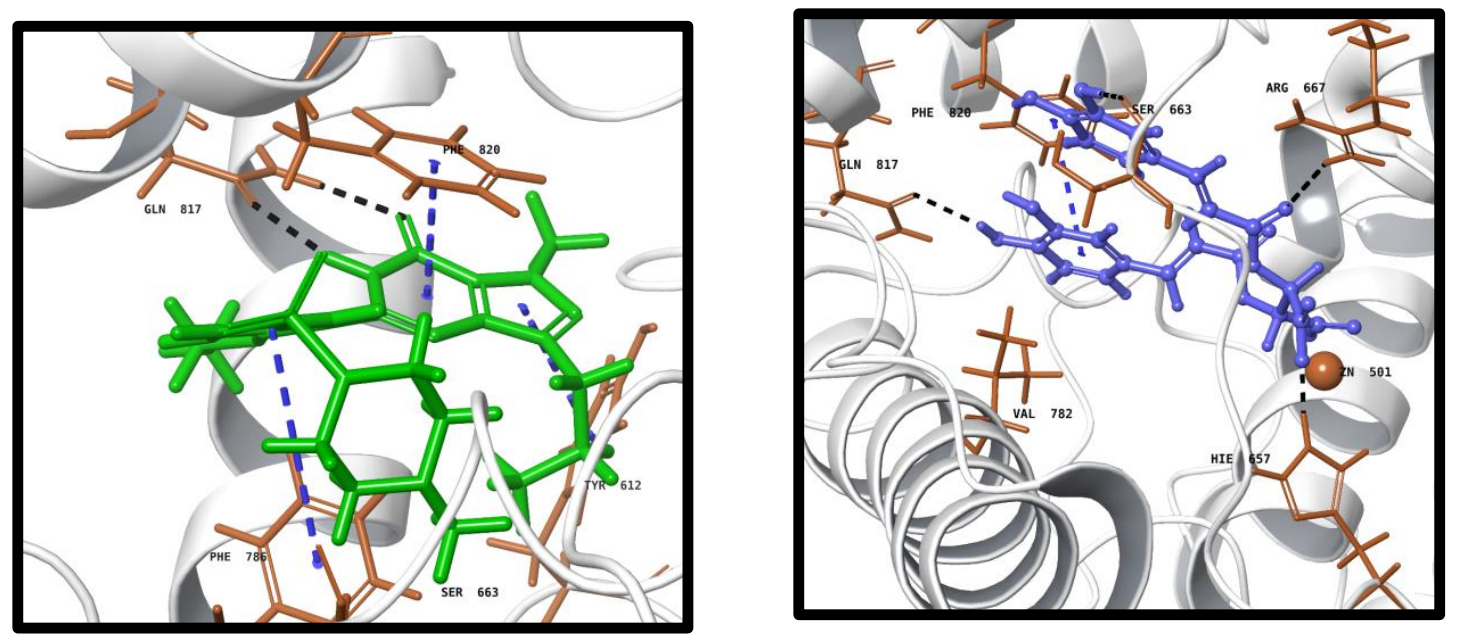

Fig 8. (A) Binding poses of Coligand; 7-(6-methoxypyridin-3-yl)-4-\{[2-(propan-2 yloxy)ethyl $]$ amino $\}-1-(2-$ propoxyethyl)pyrido[4,3-d]pyrimidin-2(1H)-one- $(0 \mathrm{H} 3)$ in the active site of PDE $5(\mathbf{B})$ Binding poses of Chicoric acid in the active site of PDE 5.

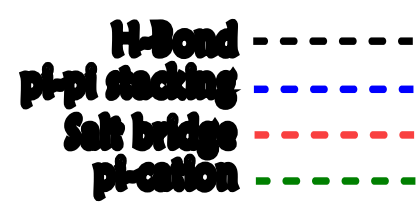




\section{International Journal of Engineering Applied Sciences and Technology, 2020 Vol. 4, Issue 11, ISSN No. 2455-2143, Pages 509-518 \\ Published Online March 2020 in IJEAST (http://www.ijeast.com)}

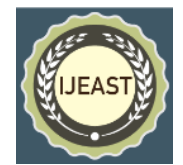

\section{DISCUSSION}

The higher access to herbs over expensive pharmaceutical drugs to treat diseases among nonindustrialized societies is fast becoming revolutionized. In some countries, it has been integrated into the health scheme despite advances in orthodox medicine. It is thought that the natural products if used properly are less harmful than synthetic products, which most often elicit some side effects [19].

Invivo studies of ethanol extract of S. monostachyus somewhat justified the claim that it has some aphrodisiac effect as suggested in folklore medicine. The mount latency per time in seconds observed in various extract doses were seen to be significantly shorter compared to the untreated subjects and it wasn't dose dependent. Similar result was obtained in number of mounts as shown. There was significant difference in sperm counts treated rats when compared to untreated rats. Intromision latency sort of showed similar result, Indicating that the agent may well be very effective in terms of arousal.

Other behavioural parameters of intromission frequency, Ejaculatory latency and post ejaculatory interval didn't show such effect.

In-silico studies was done to predict the compounds if any that may be responsible for the effect hypothesized. It was therefore important to do molecular docking studies. Molecular docking procedure is based on the ability of the compounds to interact with amino acid residues, which is a function of the protein conformation, and the assumed pose of the ligand [20]. Previously identified and characterized compounds of S.monostachyus were retrieved from PubChem using ChemAxon suite (https://www.chemaxon.com). The 44 Library of phytochemicals generated was docked against the three target proteins which may be therapeutic in erectile dysfunction viz: Phosphodiesterase 5, (PDE-5), aromatase and arginase II. Sex enhancing potentials, may include the inhibiton of the hydrolyzing action of PDE-5 with the result that active cGMP can accumulate. 'Undisturbed' and prolong the erection through increased blood flow [21]. Aromatase, is an enzyme involved in the production of estrogen that acts by catalyzing the conversion of testosterone (an androgen) to estradiol (an estrogen). Low testosterone and elevated estrogen have been implicated in the increase of the incidence of erectile dysfunction independently of one another [22]. Arginase II is a metalloenzyme, which catalyzes the hydrolysis of L-arginine to produce L-ornithine and urea. It is proposed that it competes for L-arginine and reduces Nitric oxide synthase activity in genital tissues (Nitric oxide synthase (NOS) utilizes L-arginine and oxygen as substrates to produce nitric oxide (NO) and citrulline.) thus modulating sexual function [23].

Results obtained from docking, indicated that chicoric acid and hesperidin may well inhibit PDE- 5 significantly though not as much as the co crystallized ligand 7-(6-methoxypyridin-3-yl)-4-\{[2-(propan-2yloxy)ethyl]amino $-1-(2$ propoxyethyl)pyrido[4,3d]pyrimidin-2(1H)-one- (Sildenafil) at $-11.127 \mathrm{Kcal} / \mathrm{mol}$, but was able to substantively inhibit at $-9.973 \mathrm{Kcal} / \mathrm{mol}$. While hisperidin also inhibited enzyme at -9.654 $\mathrm{Kcal} / \mathrm{mol}$. Both compounds have been identified to be components of S. monostachyus by [24].

The Admetox predictions for the compounds of interest, showed that Chicoric acid may well pass for a drug candidate as it only violated one of the Lipinski's rule of five. Which makes it rather eligible as a potential oral drug candidate [25].

\section{CONCLUSION}

This result confirmed the earlier wet experiment, that Ethanolic extract of S. monostachyus has aphrodisiac properties as it looks to have inhibitory potential on PDE-5 and as such Chicoric acid should be considered for clinical trials as an aphrodisiac drug.

\section{Acknowledgment}

We are grateful to all the researchers at the Pharmacology and Pharmacognosy Department of Madonna University, Centre for Bio-computing and Drug Development, Adekunle Ajasin University, Ondo state, for their support and team spirit, without whom efforts this work would not have been possible.

\section{REFERENCES}

1. Erhabor, J.O, Idu, M. (2017). Aphrodisiac potentials of the ethanol extract of Aloe barbadensis Mill. root in male Wistar rats, BMC Complementary and Alternative Medicine 17: pp360.

2. Malviya, N., Jain, S., Gupta, V.P., Vyas, S. (2011). Recent studies on aphrodisiac herbs for the management of male sexual dysfunction- a review. Drug Research; 68(1): pp3-8.

3. Hammoud, M.A., Jin, F., Lea, T., Maher, L., Grierson, J., Prestage, G. (2017). Off-label use of phosphodiesterase type 5 inhibitor erectile dysfunction medication to enhance sex among gay and bisexual men in Australia: results from the FLUX study. Journal of Sexual medicine ;14(6): pp774-84.

4. Ratnasooriya, W.D., Dharmasiri, M.G. (2000). Effect of Terminalia catappa seed on sexual behavior and fertility of male rats. Asian Journal of Andrology, 2: pp213 - 219.

5. Ekundayo, E.O., Ezeogu, L.I. (2006). Evaluation of antimicrobial activities of extracts of five plants used in traditional medicine in Nigeria. International Journal of Tropical Medicine, 1: pp93 - 96.

6. Ajibesin, K.K., Ekpo, B.A., Bala, D.N., Essien, E.E., Adesanya, S.A. (2008). Ethnobotanical survey of Akwa Ibom State of Nigeria. Journal of Ethnopharmacology, 115: pp387- 408. 


\section{International Journal of Engineering Applied Sciences and Technology, 2020 \\ Vol. 4, Issue 11, ISSN No. 2455-2143, Pages 509-518 \\ Published Online March 2020 in IJEAST (http://www.ijeast.com)}

7. Amazu, L.U., Antia, B.S, Okokon, J.E. (2015). Antiulcerogenic activity of Solenostemon monostachyus. Journal of Phytopharmacology, 4(2): $97-101$.

8. Obichi, E.A., Monago, C.C., Belonwu, D.C. (2015). Nutritional qualities and phytochemical compositions solenostemon monostachyus. Journal of Environmental and earth science, 5(3): pp105111.

9. Trease, E.G., Evans, C.W. (1996). Pharmacognosy (15th edition). London: Saunders Publishers; 2002. pp 42-44. 221-229 246-249, 304-336, 331-332, 391393.

10. Sofowora, A. (1993). Medicinal plants and traditional medicine in Africa. $2^{\text {nd }}$ edition, Sunshine House,Ibadan, Nigeri: Spectrum books limited Ibadan . pp134-156

11. OECD. (2001). Guidance for testing of chemicals, Acute Oral Toxicity- Acute Toxic Class Method, 17: pp423.

12. Aslam, M., Sial, A.A. (2014). Effect of hydroalcoholic extract of Cydonia oblonga miller (quince) on sexual behaviour of Wistar rats. Advanced Pharmacological Science.;2014:pp1-6.

13. Kim, S., Chen, J., Cheng, T., Gindulyte A., He, J., He, S., Li, Q., Shoemaker, B.A., Thiessen, P.A., Yu, B., Zaslavsky, L. (2018) . PubChem update: Improved access to chemical data. Nucleic acids research.;47(D1):D1102-9.

14. Schrödinger Release (2018)-1a: LigPrep, Schrödinger, LLC, New York, NY, 2018.

15. Brooks, W.H.,, Daniel, K.G., Sung, S.S., Guida, W.C. (2008). Computational validation of the importance of absolute stereochemistry in virtual screening. Journal of Chemical Information Modelling;48: pp639-645.

16. Berman, H.M., Westbrook, J., Feng, Z. (2000). The protein data bank. Nucleic Acids Research ;28:23542 .
17. Sastry, G.M., Adzhigrey, M., Day, T., Annabhimoju, R., Sherman, W. (2013). Protein and Ligand preparation: Parameters, protocols, and influence on virtual screening enrichments. Journal of Computer Aided Molecular Design, 27(3); pp221234

18. Schrödinger Release. (2018)-1c: QikProp, Schrödinger, LLC, New York, NY, 2018.

19. Okafor, J.C. (1983). Horticultural promising indigenous wild plant species of the Nigerian forest zone. Acta Horticulture, 123: pp165-176.

20. Eniafe, G.O., Metibemu, D.S., Omotuyi, I.O., Ogunleye, A.J., Inyang, O.K.,, Adelakun, N.S., Adeniran, Y.O., Enejoh, O.A., Osunmuyiwa, J.A., Shodehinde, S.A., Oyeneyin, O.E. (2018). Agemone Mexicana flavanones; opposite inverse agonists of B2- adrenergic receptor in asthma treatment. Bioinformation. 14(2): pp 60-67.

21. Basu, A., Ryder, R.E.J. (2004). New Treatment Options for Erectile Dysfunction in Patients with Diabetes Mellitus, Springer 64(23): pp2667-1688.

22. Schulster, M., Bernie, A.M., Ramasamy, R. (2016) The role of estradiol in male reproductive function. Asian Journal of Andrology; 18;pp 435 - 440.

23. Kim, N.N., Christianson, D.W., Traish, A.M., (2004) Role of arginase in the male and female sexual arousal response. The Journal of Nutrition. ;134(10 Suppl):2873S-2879S; discussion 2895S. doi: 10.1093/jn/134.10.2873S

24. Afolabi, I.S, Jalaoluwa, A.F,., Awogbidin, V.O., Amosun, P.T. (2016) Phytonutrients and bioactive compounds in the leaves of Solenostemon monostachyus. Planta Medica, 81 (S 01). S1-S381.

25. Lipinski, C.A. (2004) Lead and druglike compounds: the rule of five revolution. Drug discovery today Technology; 1(4): pp337. 